\title{
PRAÇA COLABOR[ATIVA]: NOVOS USOS DE ESPAÇOS PÚBLICOS URBANOS COM PARTICIPAÇÃO POPULAR NO CONJUNTO HABITACIONAL ANA JACINTA EM PRESIDENTE PRUDENTE-SP
}

\author{
Juliana Cavalheiro Costa, Mayara Pisssuti Albano Vieira \\ Universidade do Oeste Paulista - UNOESTE, Curso de Arquitetura e Urbanismo, Presidente Prudente, SP.
}

\section{RESUMO}

Os espaços públicos possuem grande importância ambiental e social para toda a população da cidade, além disso, ele pode garantir a segurança e convívio social entre as pessoas por meio do modo colaborativo, por isso, o objetivo do trabalho é agregar conhecimentos sobre a aplicação do conceito de placemaking, que consiste na experiência coletiva, unindo espaços públicos e a comunidade para a implantação de uma horta e pomar comunitário, em um vazio urbano localizado no Conjunto Habitacional Ana Jacinta, na cidade de Presidente Prudente-SP. Deste modo, foi preciso a realização de pesquisas bibliográficas, sobre os conjuntos habitacionais e os presentes na cidade de Presidente Prudente, juntamente com pesquisa documental e levantamentos de campo.

Palavras-chave: Conjunto Habitacional, Espaço Público, Praça colaborativa, Placemaking, Presidente Prudente - SP.

\section{COLABOR [ACTIVE] SQUARE: NEW USES OF URBAN PUBLIC SPACES WITH POPULAR PARTICIPATION IN ANA JACINTA HABITATIONAL SETTLEMENT IN PRUDENTE PRESIDENT-SP}

\begin{abstract}
The public spaces have great environmental and social importance for the entire population of the city, besides, it can guarantee security and social interaction among people through the collaborative way, so the objective of the work is to aggregate knowledge about the application of the concept of placemaking, which consists of collective experience, uniting public spaces and the community for the implantation of a community garden and orchard, in an urban emptiness located in the Ana Jacinta Housing Complex, in the city of Presidente Prudente-SP. In this way, it was necessary to carry out bibliographic research on the housing complexes and those present in the city of Presidente Prudente, along with documentary research and field surveys.
\end{abstract}

Keywords: Housing Set, Public Space, Collaborative Square, Placemaking, Presidente Prudente - SP. 


\section{INTRODUÇÃO}

O processo de urbanização do Brasil intensificou-se na segunda metade do século XX e, pela primeira vez na história, na década de 1970, a população urbana supera a população residente na área rural, acentuando a crise urbana (SANTOS, 2005). Neste contexto, ocorre um enorme movimento de construção de cidade legal e ilegal, com forte expansão da malha voltada à áreas habitacionais, contudo, concomitantemente à necessidade de moradia, torna-se preciso pensar em sistemas de infraestrutura, equipamentos urbanos e espaços de lazer públicos e de qualidade que supram as necessidades dos citadinos (MARICATO, 2001).

A partir da criação do Banco Nacional da Habitação (BNH), pelo Regime Militar na década de 1960, a produção do espaço urbano no Brasil teve suas características modificadas pela política habitacional estabelecida através de duas vertentes: uma voltada à classe média e, outra, que provocou o agravamento do processo de periferização que deslocou a moradia das classes mais baixas para as franjas da malha urbana (BONATES, 2008).

Conforme afirma Maricato (2001, p. 20), "Infelizmente o financiamento imobiliário não impulsionou a democratização do acesso à terra", e como reflexo da exclusão social e segregação espacial nítida no modelo de urbanização adotado no país, o mercado não se abriu para a maioria das pessoas que necessitavam de moradia - as pertencentes às classes populares.

Outro problema envolvendo os Conjuntos Habitacionais são os espaços públicos voltados para o lazer, eles não correspondem às necessidades reais de seus moradores, além de não receberem, na maioria das vezes, manutenção adequada. $O$ descaso com tais espaços desde o projeto até a conservação adequada, faz com que os moradores não se sintam responsáveis o suficiente para cuidar, e acabam não se importando quando ocorre depredação e vandalismos, prejudicando ainda mais a qualidade dos mesmos. Os espaços públicos projetados de modo adequado colaboram para a igualdade social; quando os espaços públicos são negligenciados ou privatizados, a cidade se torna cada mais segregada (SÃO PAULO, 2016).

Presidente Prudente - SP, desde a década de 1960 apresentou a construção de conjuntos habitacionais direcionados à população de baixa renda, entretanto, a maioria deles, inserido na periferia da cidade, nas franjas da malha urbana. Entre os quais, pode ser destacado o Conjunto Habitacional Ana Jacinta cuja construção foi iniciada nos últimos anos da década de 1980 e as unidades entregues no início da década de 1990 (ALBANO, 2013).

Diante do exposto, o presente trabalho tem por objetivo desenvolver pesquisas para escolha e posterior análise de uma área, bem como diretrizes projetuais que embase o desenvolvimento, num outro momento, um projeto de uma Praça Colaborativa no referido conjunto habitacional, através de práticas conhecidas como Placemaking.

\section{METODOLOGIA}

A metodologia utilizada na pesquisa que gerou este artigo baseou-se em pesquisas bibliográficas, documentais e de campo. Numa primeira foram selecionadas e estudadas as principais obras referentes ao conceito de espaço público e criação de espaços colaborativos, bem como sobre Placemaking. Numa segunda etapa, realizou-se pesquisas documentais junto a Prefeitura Municipal de Presidente Prudente - SP, cujo material necessário está disponível em seu website oficial, para se buscar a relação de espaços públicos ociosos no referido bairro, e posteriores escolhas e análises propostas, tais como: 
uso e ocupação do entorno, levantamento do gabarito de altura das edificações próximas à área escolhida, análises de insolação, ventilação, planialtimétrica, entre outras, que forem pertinentes e necessárias para a elaboração das diretrizes projetuais. Por fim, para complementar as análises possibilitadas pelos levantamentos documentais, foram realizadas pesquisas in loco, para levantamento fotográfico, medições e melhor compreensão das condicionantes existentes.

\section{ESPAÇOS PÚBLICOS E O PLACEMAKING}

Matos (2010) conceitua o termo espaços públicos como espaços que por natureza são mais abertos e a primeira função que ele deve obter é a facilidade de acesso, são aqueles de toda a comunidade e que não pertence a ninguém em especial, e que todos podem usar com os mesmos direitos.

Sendo assim, para potencializar o uso de um espaço público é necessário organizar a heterogeneidade natural que existe na cidade, de acordo com Rolnik (2000, p. 5), é importante:

[...] fomentar a convivência entre pessoas diferentes, diminuindo a segregação e as distancias sociais, suprimindo os guetos, atuando com solidariedade, como uma coletividade que amplie, incentive e aumente a comunicação entre os projetos de vida pessoais e coletivos.

Ao longo do tempo, foram criados metodologias e conceitos com os objetivos de gerar uma conexão entre as pessoas que vivem na cidade e incentivar a noção de pertencimento nos espaços públicos, dentre eles pode-se citar o placemaking. Segundo Santiago (2016, p. 24):

A palavra "placemaking" pode ser traduzida livremente para o português como "fazer lugares". Os lugares mencionados aqui são espaços públicos que estimulam interações interpessoais e entre as pessoas e a cidade, promovendo comunidades saudáveis e felizes. Placemaking é, ao mesmo tempo, um conceito amplo e uma ferramenta prática para melhorar um bairro, uma cidade ou uma região. Placemaking é um movimento que repensa os espaços públicos como o coração de toda a comunidade em relação à cidade.

Esse conceito foi criado por uma Organização Não Governamental - ONG chamada Project for Public Spaces - PPS, instituído pelo trabalho de William "Holly" Whyte, em meados dos anos de 1970, e foi baseado no pensamento de que todos os espaços públicos deveriam ser vistos de maneira única, ou seja, buscar a valorização deles com a ajuda e a necessidade daqueles que vivem e usam seu entorno, fomentando a noção de pertencimento entre a população e os espaços públicos.

Dowbor (1995) afirma que a participação comunitária é um mecanismo de maior racionalidade de regulação das atividades em âmbito social, relacionadas a urbanização, a pequena e média produção, e propaga-se como um meio fundamental para o equilíbrio do conjunto de atividades na esfera macroeconômica.

Muitos são os benefícios que ocorrem quando acontece esse tipo de participação popular dentro dos projetos públicos, entre elas a ampliação da segurança. Os próprios moradores que participam dessas oficinas acabam se tornando os "olhos da rua", e ajudam a cuidar do espaço público. Todas as ações propostas pela ONG pedem o auxílio da própria população tanto no momento de criação do projeto como também na fase de implementação, assim todos os anseios são escutados, analisados e estudados para prever a viabilidade de cada projeto, para que ele não somente dialogue com o seu entorno imediato, 
mas sim com toda a cidade, assim afirma a ONG Project for Public Spaces - PPS, a partir da descrição em seu website.

O placemaking também contribui para que as pessoas possam ter a sua qualidade de vida assegurada dentro desses espaços, proporcionar bem-estar, felicidade e saúde são desejos que o desenho colaborativo quer trazer para espaços, que muitas vezes se encontram vazios, sem vida e até mesmo sendo um incomodo para toda a comunidade.

\section{PRESIDENTE PRUDENTE E O CONJUNTO HABITACIONAL ANA JACINTA}

De acordo com o IBGE (2017), a cidade de Presidente Prudente é uma cidade média do interior do oeste paulista, fazendo divisa com os estados do Paraná e Mato Grosso do Sul, (figura 01), sua população estimada se aproxima de 225.000 mil pessoas, e a sua área territorial aproxima-se a $560 \mathrm{~km}^{2}$.

Sua fundação data de 1917, contudo, foi a partir da década de 1960 que inicia-se a implementação de conjuntos de habitação social voltados à população de baixa renda, tendo como característica geral, a localização na periferia da cidade, nas franjas da malha urbana. Entre os quais, pode ser destacado o Conjunto Habitacional Ana Jacinta cuja construção foi iniciada nos últimos anos da década de 1980 e as unidades entregues no início da década de 1990 (ALBANO, 2013).

Figura 01. Localização da Área de Estudo Dentro do Município de Pres. Prudente, No Conjunto Habitacional Ana Jacinta.

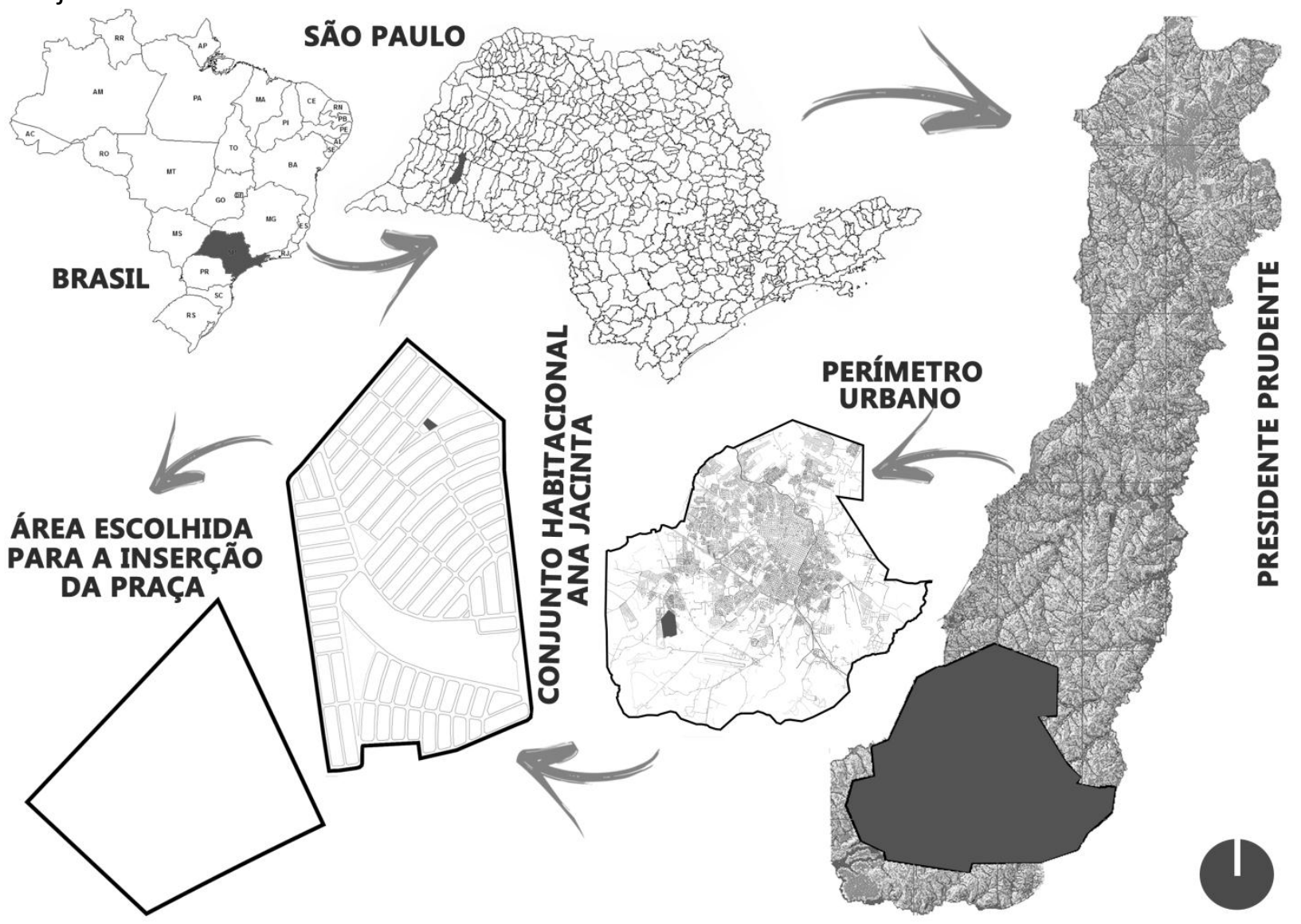

Fonte: Google Maps. Elaboração da autora, 2018. 
A área escolhida distava cerca de $8 \mathrm{~km}$ do centro da cidade, configurando segregação socioespacial e penalizando os moradores com a dificuldade de acesso, e longas distâncias a serem percorridas diariamente em busca de comércios e serviços. Sendo assim, em função da necessidade dos moradores, com o passar dos anos, um sub-centro. Os comércios existentes no bairro possibilitam que as pessoas possam satisfazer as suas necessidades imediatas, porém, não garante uma diversidade funcional, pois têm a característica de vizinhança.

A área de intervenção para o projeto (Figura 1) faz parte da um lote dentro do Conjunto Habitacional Ana Jacinta e é dedicado à área institucional, conforme o seu mapa do zoneamento do município, porém as escolas localizadas no lote em estudo não ocupam todo o terreno, por isso, uma parcela se tornou um vazio urbano. Apesar de ser um vazio físico e de uso, o terreno possui trajetos feitos pela própria comunidade, que se tornaram caminhos do desejo, são apropriações espontâneas da população do Conjunto Habitacional Ana Jacinta para chegar até os serviços de maneira mais rápida, sem fazer o acesso pela calçada por meio da esquina.

Figura 02. ESTUDOS APRESENTANDO OS EQUIPAMENTOS URBANOS NA ÁREA ESCOLHIDA.

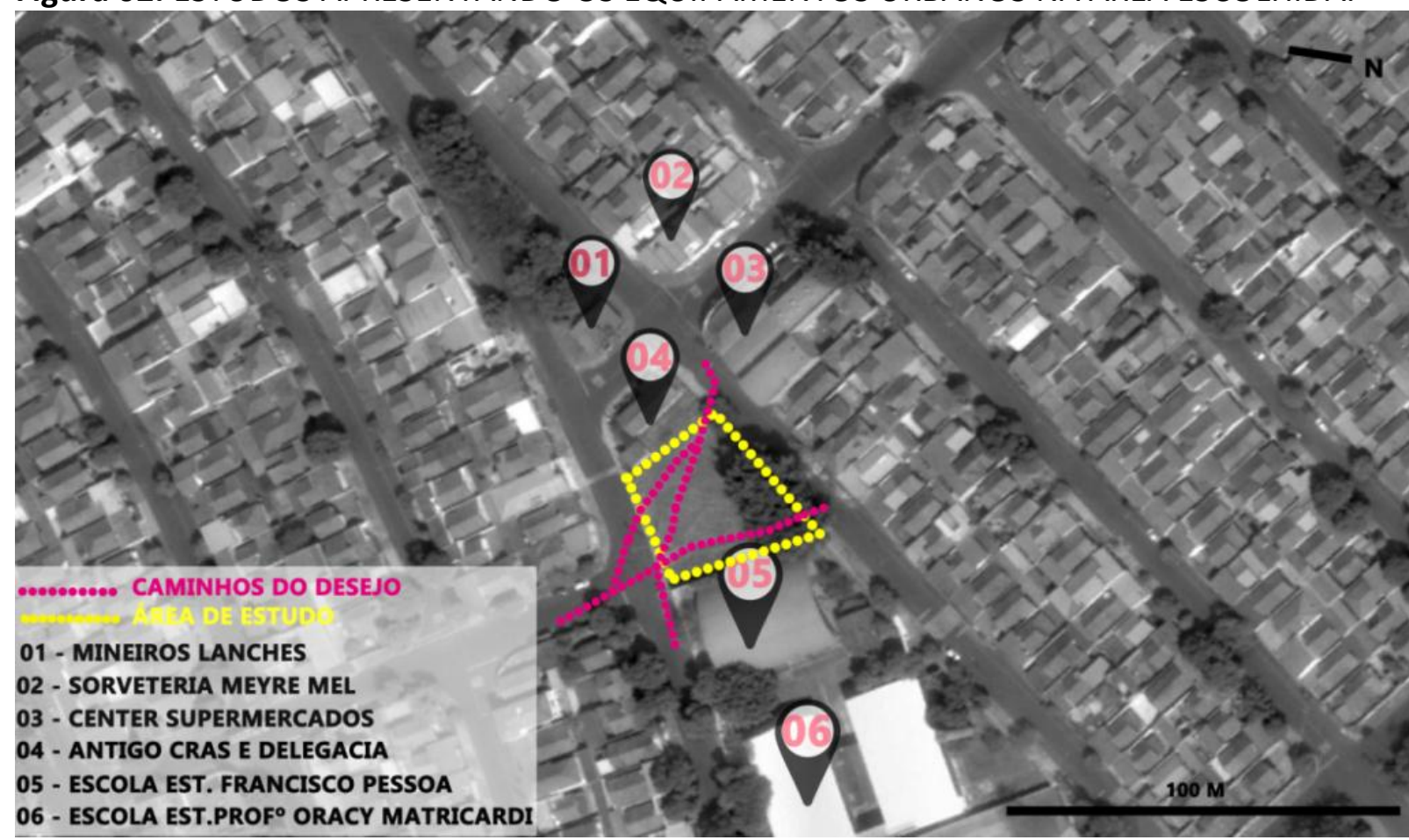

FONTE: Google Earth. Elaboração da autora, 2018.

Após as análises da área, foram formuladas diretrizes projetuais, que estão apoiadas, na tentativa de evidenciar e dar melhores condições para esses caminhos, para que a travessia dentro da área se torne mais agradável, bem como trazer novos usos para a área, como a implementação de uma horta e pomar urbano, garantindo uma maior integração entre os moradores do bairro, assim como a segurança, pois a área será observada com maior frequência, principalmente por aqueles que se propuserem a cuidar dos novos espaços inseridos.

O conceito atribuído para o projeto é pautado nos caminhos feitos pelos moradores. Caminho, de acordo com o Dicionário Aurélio online, representa andar em uma direção, possuir um rumo, um destino escolhido, para isso o partido arquitetônico quer dar 
melhores condições para os mesmos, trazendo um trajeto mais agradável e novos usos citados anteriormente garantindo uma convivência social entre os moradores por meio da metodologia de placemaking para a produção e implementação do projeto dentro da área escolhida.

Áreas de bancos e convívio social também fazem parte do projeto para incentivar a permanência da população no local. Entende-se também que, quando ocorrer o beneficio da população por conta da horta e pomar comunitário, assim como espaços para convívio social também estará ocorrendo práticas relacionadas ao placemaking, pois a metodologia quer repensar espaços públicos para que aumente a qualidade de vida e o bem-estar da população.

\section{CONSIDERAÇÕES FINAIS}

A partir de tal pesquisa, foi possível identificar que o Conjunto Habitacional Ana Jacinta, não foi pensado para que as pessoas pudessem obter uma boa qualidade de vida tanto nas no referente ao projeto arquitetônico das residências, que foram reduzidas para o enquadramento num programa do Governo Federal, como os seus espaços públicos, que não receberam usos que fossem capazes de envolver a comunidade, com isso, pode concluir que a inserção de uma praça com usos de horta e pomar comunitário poderá garantir a essa população uma integração de convívio social e cuidado com os espaços públicos, justamente pela sua formação estar atrelada ao movimento colaborativo, por meio do placemaking.

\section{REFERENCIAS}

ALBANO, Mayara Pissutti. A importância do Planejamento Urbano Ambiental: a habitação social e a expansão urbana em Presidente Prudente-SP. Dissertação (Mestrado) Universidade do Oeste Paulista, Presidente Prudente, 2013.

BONATES, Maria Fialho. O Programa de Arrendamento Residencial - PAR: acesso diferenciado à moradia e à cidade. Revista de Pesquisa em Arquitetura e Urbanismo, v.7, n. 1, p. 147-164, 2008. Disponível em: http://www.arquitetura.eesc.usp.br/revista_risco/ Risco7-pdf/02_art10_risco7.pdf. Acesso em: 8 nov 2008.

DOWBOR, LADSLAU. O que é Poder Local? Editora Brasiliense, Coleção Primeiros Passos, São Paulo 1995.

MARICATO, Ermínia. Brasil cidades: alternativas para a crise urbana. Petrópolis, RJ: Vozes, 2001.

MATOS, Fatima Loureiro de. Espaços públicos e qualidade de vida nas cidades - o caso da cidade Porto. OBSERVATORIUM: Revista Eletrônica de Geografia, v.2, n.4, p.17-33, jul. 2010. Disponível em: $<$ http://www.observatorium.ig.ufu.br/pdfs/2edicao/n4/Espacos_publicos.pdf >. Acesso em 27 mar. 2018.

ROLNIK, Raquel. O lazer humaniza o espaço. In: SESC SP. (Org.). Lazer numa sociedade globalizada. São Paulo: SESC São Paulo/World Leisure, 2000. Disponível em: <https://raquelrolnik.wordpress.com/2008/08/19/o-lazer-humaniza-o-espaco-urbano/>. Acesso em: 02 out. 2017. 
SANTIAGO, Paola Caiuby. Produção: Guia do Espaço Público. 2016. Disponível online em: <http://www.placemaking.org.br/home/wp-content/uploads/2015/03/Guia-doEspa\%C3\%A7o-P\%C3\%BAblico1.pdf>. Acesso em 13 mar. 2018.

SANTOS, Milton. A urbanização brasileira. 5.ed. São Paulo: Universidade de São Paulo, 2005.

SÃO PAULO, Governo do Estado de. Guia do Espaço Público. Conexão Cultural, 2a edição, 2016. 